\title{
DESIGN OF A NEW DIHEDRAL-ANGLE-CONTROLLED MOLECULAR SCISSORS: A DFT INVESTIGATION
}

\author{
M. Samadizadeh ${ }^{1}$, S.S. Gorgani ${ }^{2}$ \\ ${ }^{1}$ Department of Chemistry, Faculty of Basic Science, Central Tehran Branch, Islamic Azad University, Tehran, Iran \\ ${ }^{2}$ Young Researches and Elite Club, Central Tehran Branch, Islamic Azad University, Tehran, Iran \\ E-mail: sarasoleimani240@yahoo.com
}

Received July, 16, 2015

\begin{abstract}
DFT calculations are employed to investigate the effects of the addition of a photoisomerizable stilbene unit to Aida's molecular scissors on relative energies, dipole moments, and kinetic stability according to HOMO_LUMO energy gaps and amplitude of the open-close motion of blade moieties. The most obvious finding emerging from this study is the coming into existence of a new pair of molecular scissors operated by two photoswitchable units. Based on photoisomerization of azobenzene and stilbene units, four conformations appear for these new molecular scissors: cis-cis, cis-trans, trans-cis, and trans-trans. The HOMO-LUMO energy gaps promise that all isomers are kinetically stable. The other important finding is that in these new molecular scissors the dihedral angle between the two blade moieties can be controlled and measured through the open-close motion and the blade parts can adopt two middle states in addition to open-close forms.
\end{abstract}

DOI: $10.15372 / J S C 20150708$

K e y w o r d s: molecular scissors, photoisomerization, DFT, azobenzene, stilbene, open-close motion.

\section{INTRODUCTION}

Configurational changes [1], in particular cis-trans isomerization of double bonds, have been extensively studied [2,3]. Although this small amplitude motion is not generally sufficient for direct exploitation as a machine, it can supply an infinitely useful photoswitchable control mechanism for more complex systems. The photoisomerization of stilbenes, which has been greatly studied for well over 50 years [4], and the photoisomerization of azobenzenes [5] are the examples of this type of systems which can be controlled by the external stimulus. The simultaneous existence of these photoisomerizable units in a molecule causes four structures: a) trans-azobenzene, cis-stilbene b) cisazobenzene, $c i$ s-stilbene $c$ ) cis-azobenzene, trans-stilbene $d$ ) trans-azobenzene, trans-stilbene (Fig. 1).

Designing and preparing new molecular motors and machines which are operated by these photoswitchable units attract great attention, not only for basic researches but also for growth and development of nanoscience and related investigations to nanotechnology [6]. Among molecular machines, molecular scissors have specific importance due to their repeated function. These molecular machines are recognized as a host sustaining segments and pieces in its two arms. The design of the first lightdriven chiral molecular scissors was reported by Aida et al. in 2003 [ 7 ]. In this new molecular device, the motion of photoisomerizable azobenzene unit could be exploited to regulate the movement of the blade parts under photochemical control [8]. DFT calculations indicated that in trans configuration of azobenzene unit the blade parts were closed, while in cis configuration they were open [9]. In this

(C) Samadizadeh M., Gorgani S.S., 2015 
Fig. 1. Photoisomerization of azobenzene and stilbene together<smiles>[R]c1ccc(/C=C\c2ccc(/N=N/c3ccc(/C=C/c4cc(/C=C/c5ccc(/N=N\c6ccc(/N=N/c7ccc(/C=C/c8ccc([R])cc8)cc7)cc6)cc5)ccc4[R])cc3)cc2)cc1</smiles>

scissors-like molecule, the blade parts could not be in a middle state between the open-close forms. In a new design, in this paper, some structural changes were created in the previous molecular scissors by exploiting the stilbene unit as another photoisomerizable part which could be connected with azobnzene unit through ethylene linkage to give the blade moieties two middle-states in addition to open-close motion.

\section{COMPUTATIONAL DETAILS}

The geometric parameters of the stationary points were optimized utilizing density functional theory (DFT). To obtain the minimum, the optimizations without symmetry constraints were performed. The Becke three-parameter exchange functional with the correlation functional of Lee, Yang, and Parr (B3LYP) [ 10-12] and the 3-21g* basis set [13,14] were employed for the geometry optimizations. The natures of various stationary points were checked by the number of imaginary frequencies obtained from harmonic vibrational frequency calculations [15]. The DFT approach was also applied to gain 0.97 scaled zero point vibrational energy corrections. All calculations were performed with the Gaussian03 program package [16]. Optimized coordinates of whole structures are included in the Supporting Information.

\section{RESULTS AND DISCUSSION}

Inspired by Aida's molecular scissors operated by one photoswitchable azobenzene unit, in this work we suggested a new design of molecular scissors operated by two photoswitchable azobenzene and stilbene units. Aida's molecular scissors consisted of two phenyl groups as the blade moieties, $1,1^{\prime}, 3,3^{\prime}$-tetrasubstituted ferrocene as the pivot part, and two phenylene groups as the handle parts, which were linked with an azobenzene unit through ethylene linkages. In this scissors-like molecular machine the cis-trans photoisomerization of the azobenzene unit was exploited to induce the angular motion of the ferrocene unit, resulting in the open-close motion of the blade moieties. The cis isomer was caused by light irradiation of $\lambda=350 \mathrm{~nm}$, while the exposure to visible light $(\lambda>400 \mathrm{~nm})$ again led to the trans isomer.

Initially, we decided to calculate the basic information about Aida's molecular scissors using B3LYP and the $3-21 \mathrm{G}^{*}$ basis set for comparison with the new designed dihedral - angle - controlled molecular scissors. Fig. 2 shows the optimized

Fig. 2. Structural formula and graphic representation of Aida's molecular scissors based on the photoisomerization of azobenzene
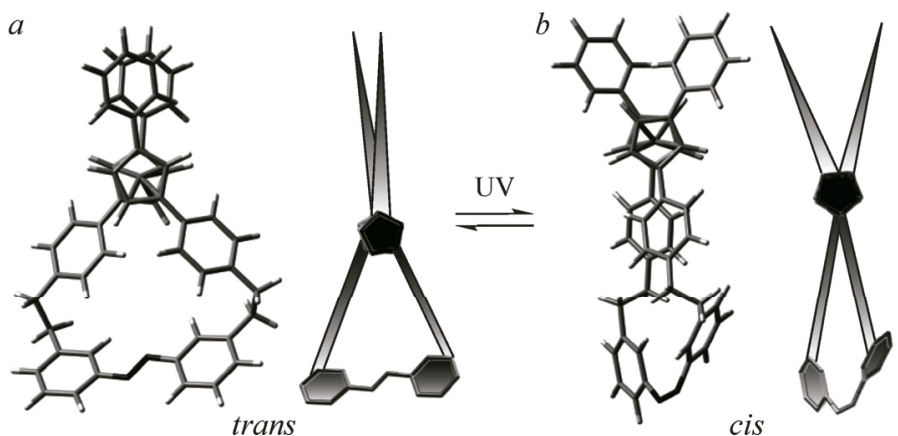
T a b l e 1 structures of the trans (left) and cis

B3LYP/3-21G* Energies of molecules $(\mathrm{kcal} / \mathrm{mol})$, relative energies $\left(\Delta E_{\mathrm{rel}}, \mathrm{kcal} / \mathrm{mol}\right)$ along with their dipole moments $(D), \mathrm{HOMO}$ - LUMO energy gaps $(\mathrm{eV})$, and dihedral angles (deg.) for Aida's molecular scissors

\begin{tabular}{c|c|r|c|c|c}
\hline Structure & $E$ & \multicolumn{1}{|c|}{$\Delta E_{\text {rel }}$} & $D$ & $\Delta E_{\text {номо-цимо }}$ & $\mathrm{C}-\mathrm{C}-\mathrm{C}-\mathrm{C}$ \\
\hline cis & -2061633.32 & 15.55 & 3.49 & 3.31 & 58.1 \\
trans & -2061648.87 & 0.00 & 0.41 & 3.00 & 8.9
\end{tabular}

(right) forms of Aida's molecular scissors, which we obtained from the DFT calculation, and the schematic representation of the open-close motion induced by the photoisomerization of the azobenzene unit.

In the trans form, the blade moieties were close to each other with a bite angle of $8.9^{\circ}$. On the other hand, the blade phenyl groups in the cis form were separated from each other with a bite angle of $58.1^{\circ}$. Table 1 lists the energies for cis-trans molecules, relative energies $\left(\Delta E_{\mathrm{rel}}\right)$, dipole moments, magnitude of HOMO - LUMO energy gaps, and bite angles of the blade phenyl groups $(\mathrm{C}-\mathrm{C}-\mathrm{C}-\mathrm{C}$ dihedral angel) for Aida's molecular scissors. As can be seen, the cis isomer was about $15.55 \mathrm{kcal} / \mathrm{mol}$ less stable than the trans isomer and showed a larger dipole moment relative to the trans form of Aida's molecular scissors (3.49 and 0.41, respectively). High HOMO_LUMO energy gaps confirmed the kinetic stability of cis-trans isomers.

Then in a new innovation we exploited azobenzene and stilbene units in molecular scissors simultaneously to produce a more controlled and measured mechanical motion. By that work, a new design of molecular scissors was created which consisted of two phenyl groups as the blade moieties, $1,1^{\prime}, 3,3^{\prime}$-tetrasubstituted ferrocene as the pivot part, and azobenzene and stilbene units as the handle parts, which were connected with each other through the ethylene linkage. The involvement of two photoswitchable units isomerized at separate wavelengths from each other for operating the mechanical motion in this new molecular scissors caused the development of the open-close motion of the blade parts and the dihedral angle between the two phenyl groups in the blade moieties could be controlled and measured through the open-close motion. With these observations, by geometry optimizations using B3LYP and the 3-21G* basis set, four minimum optimized structures were obtained: a) cis-azobenzene, cis-stilbene b) cis-azobenzene, trans-stilbene c) cis-azobenzene, trans-stilbene d) trans-azobenzene, trans-stilbene (Fig. 3).

The dihedral angles between the phenyl groups in the blade parts of these structures are $70.2^{\circ}$, $38.1^{\circ}, 0.66^{\circ}$, and $0.22^{\circ}$ respectively (Table 2 ). As compared to Aida's molecular scissors (Table 1 ), the
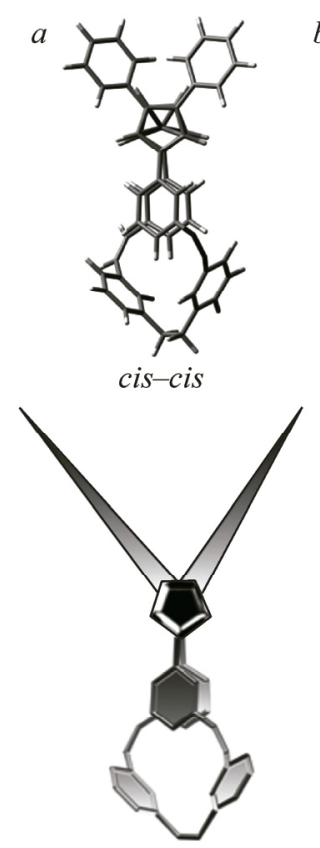
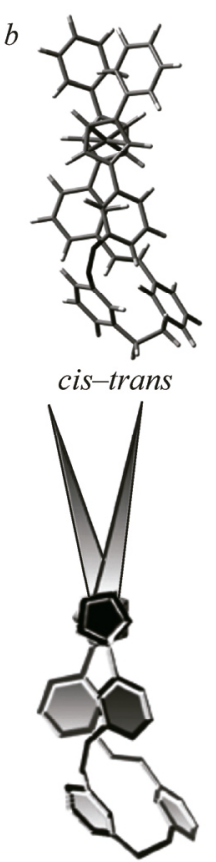
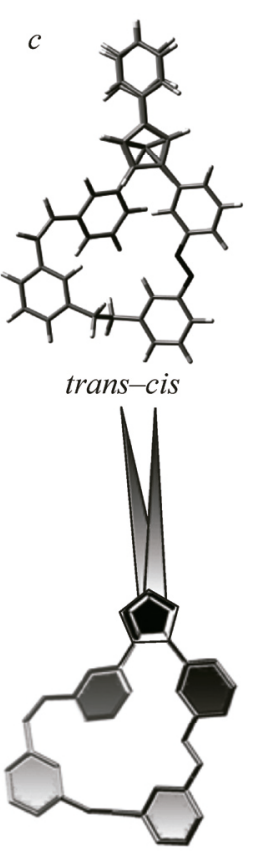
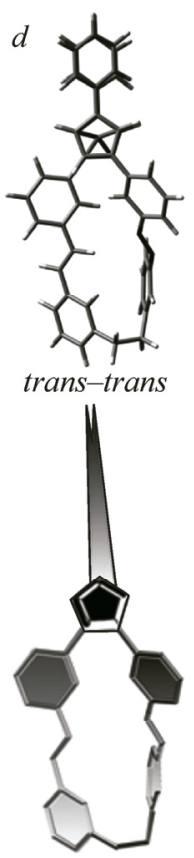

Fig. 3. Optimized conformations of photoisomerizable chiral molecular scissors (top) and schematic representation of its open-close motion induced by the photo isomerization of the azobenzene and stilbene units (bottom) 
B3LYP/3-21G* Energies of molecules $(\mathrm{kcal} / \mathrm{mol})$, relative energies $\left(\Delta E_{\mathrm{rel}}, \mathrm{kcal} / \mathrm{mol}\right)$ along with their dipole moments (Debye), HOMO_LUMO energy gaps $(\mathrm{eV})$, and dihedral angles (deg.) for the studied molecular scissors

\begin{tabular}{l|r|r|c|c|c}
\hline \multicolumn{1}{c|}{ Structure } & $E$ & $\Delta E_{\text {rel }}$ & $D$ & $\Delta E_{\text {Номо-LUмо }}$ & $\mathrm{C}-\mathrm{C}-\mathrm{C}-\mathrm{C}$ \\
\hline cis-cis & -2060858.81 & 21.28 & 3.60 & 3.58 & 70.2 \\
cis-trans & -2060862.29 & 17.81 & 3.11 & 3.47 & 38.14 \\
trans-cis & -2060879.69 & 0.40 & 0.56 & 3.19 & 0.66 \\
trans-trans & -2060880.09 & 0.00 & 0.40 & 3.12 & 0.22
\end{tabular}

amplitude of the open-close motion of the blade parts increased $\left(70.2-0.22^{\circ}\right)$ and had two middle values of $38.1^{\circ}$ and $0.66^{\circ}$. Among these four isomers, the trans-trans isomer was the most stable one. Trans-cis and cis-trans isomers were about 0.40 and $17.81 \mathrm{kcal} / \mathrm{mol}$ less stable than the transtrans one. The cis - cis isomer was the least stable one (higher in energy than the trans-trans isomer by $21.28 \mathrm{kcal} / \mathrm{mol}$ ). These results are due to the fact that the isomerization process involves a decrease in the distance between the two carbon atoms in position 4 of the aromatic rings of azobenzene and stilbene units. Trans-azobenzene and trans-stilbene are almost flat, whereas the cis isomers show an angular geometry since the steric interactions force the aromatic rings out of the plane and hinder conjugation (Fig. 4) [17, 18$]$.

The dipole moments of these isomers were $3.60 \mathrm{D}, 3.11 \mathrm{D}, 0.56 \mathrm{D}$ and $0.40 \mathrm{D}$ respectively. Generally, the isomerization in particular cis-trans isomerization of azobenzene causes a change in the dipole moment of about 0.5 Debye in the trans forms in comparison with 3.1 Debye in the cis forms [19]. As can be seen, this fact was confirmed by the results. The HOMO-LUMO energy gaps for a) cis-azobenzene, cis-stilbene b) cis-azobenzene, trans-stilbene c) cis-azobenzene, trans-stilbene d) trans-azobenzene, trans-stilbene were similar to the HOMO-LUMO energy gaps of Aida's molecular scissors and showed $3.58 \mathrm{eV}, 3.47 \mathrm{eV}, 3.19 \mathrm{eV}$, and $3.12 \mathrm{eV}$ respectively. The HOMOLUMO energy gap can be related to the kinetic stability of various $\pi$ electron systems [20 ]. The high HOMO - LUMO energy gaps, which were calculated in this study, promised that all isomers were kinetically stable (Table 2 ).

\section{CONCLUSIONS}

This computational study showed that an increase in a new photoswitchable part, such as stilbene which isomerized at a separate wavelength from azobenzene, as compared to the previous molecular scissors, introduced a new pair of molecular scissors. Under the photochemical process, the dihedral angle between the two phenyl groups of the blade moieties could be controlled and measured through the open-close motion. In these calculations, the azobenzene and the stilbene units isomerized into their cis-trans conformations under UV-VIS irradiation. DFT computations predicted four optimized structures for these new molecular scissors, which were kinetically stable.

The development of molecular devices that can perform specific mechanical works by means of photoswitchable units plays an important role in the improvement of molecular machines operated by two moving components. This study shows a new gate for the development of molecular scissors consisting of many joint parts induced by two photoresponsive units.
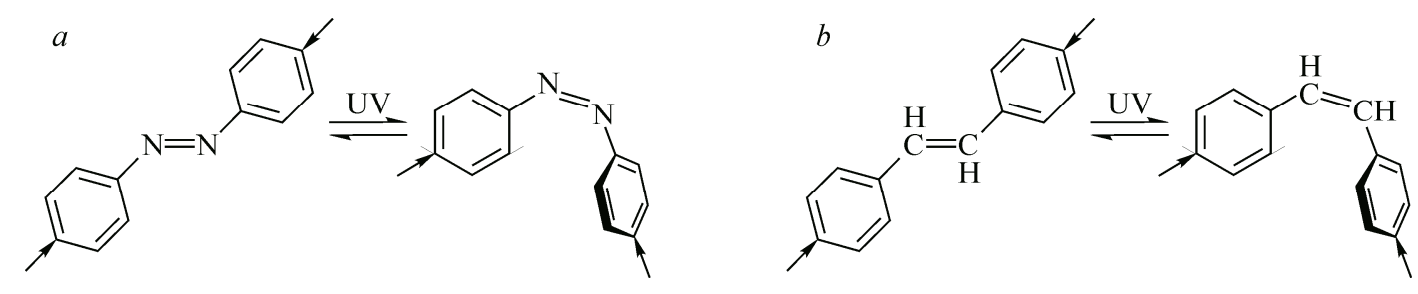

Fig. 4. Cis-trans conformations of azobenzene (left) and stilbene (right) 


\section{REFERENCES}

1. Fyfe M.C.T., Glink P.T., Menzer S., Stoddart J.F., White A.J.P., Williams D.J. // Angew. Chem. Int. Ed. - 1997. - 36. - P. 2068 - 2070.

2. Eliel E.L., Wilen S.H. Stereochemistry of organic compounds. - New York: Wiley-Interscience, 1994.

3. Dugave C., Demange L. // Chem. Rev. - 2003. - 103. - P. $2475-2532$.

4. (a) Waldeck D.H. // Chem. Rev. - 1991. - 91. - P. 415 - 436; (b) Meier H. // Angew. Chem., Int. Ed. - 1992. - 31. - P. 1399 - 1420; (c) Saltiel J., Sears D.F. Jr., Ko D.-H., Park K.-M. In: CRC Handbook of Organic Photochemistry, Photobiology / Eds. W.M. Horspool, P.-S. Song, CRC, Boca Raton, 1995. - P. 3 - 15.

5. Suginome H. In: CRC Handbook of Organic Photochemistry, Photobiology / Eds. W.M. Horspool, P.-S. Song, CRC, Boca Raton, 1995. - P. $824-840$.

6. (a) Kay E.R., Leigh D.A., Zerbetto F. // Angew. Chem., Int. Ed. - 2007. - 46. - P. 72 - 191; (b) Durgun E., Grossman J.C. // J. Phys. Chem. Lett. - 2013. - 4. - P. 854 - 860; (c) Balzani V., Credi A., Silvi S., Venturi M. // Chem. Soc. Rev. - 2006. - 35. - P. 1135 - 1149.

7. Muraoka T., Kinbara K., Kobayashi Y., Aida T. // J. Am. Chem. Soc. - 2003. - 125. - P. 5612/5613.

8. (a) Muraokal T., Kinbaral K., Aida T. // Nature. - 2006. - 440. - P. 512/513; (b) Raymo F.M. // Angew. Chem., Int. Ed. - 2006. - 45. - P. 5249 - 5251.

9. (a) Merino E., Ribagorda M. // Beilstein J. Org. Chem. - 2012. - 8. - P. 1071 - 1090; (b) Muraoka T., Kinbara K. // J. Photochem. Photobiol., C. - 2012. - 13. - P. 136 - 147; (c) Zheng Y.B., Hao Q., Yang Y.-W., Kiraly B., Chiang I., Huang T.J. // J. Nanophotonics. - 2010. - 4. - P. 4; (d) Kinbara K., Aida T. // Chem. Rev. - 2005. - 105. - P. 1396.

10. Becke D. // Phys. Rev. A. - 1988. - 38. - P. $3098-3100$.

11. Becke D. // J. Chem. Phys. - 1993. - 98. - P. 5648 - 5652.

12. Lee C., Yang W., Parr R.G. // Phys. Rev. B. - 1988. - 37. - P. $785-789$.

13. Hariharan P.C., Pople J.A. // Mol. Phys. - 1974. - 27. - P. $209-214$.

14. Pople J.A. // Chem. Phys. - 1982. - 77. - P. $3654-3665$.

15. Hehre W.J., Radom L., Schleyer P.v.R., Pople J.A. // J. Comput. Chem. - 1986. - 7. - P. 379.

16. Frisch M.J., Trucks G.W., Schlegel H.B., Scuseria G.E., Robb M.A., Cheeseman J.R. Jr., Montgomery J.A., Vreven T., Kudin K.N., Burant J.C., Millam J.M., Iyengar S.S., Tomasi J., Barone V., Mennucci B., Cossi M., Scalmani G., Rega N., Petresson P.G.A., Nakatsuji H., Hada M., Ehara M., Toyota K., Nakai H., Klene M., Li X., Knox J.E., Hratchian H.P., Cross J.B., Bakken V., Adamo C., Jaramillo J., Gomperts R., Stratmann R.E., Yazyev O., Austin A.J., Cammi R., Pomelli C., Ochterski J.W., Ayala P.Y., Morokuma K., Voth G.A., Salvador P., Dannenberg J.J., Zakrzewski V.G., Dapprich S., Daniels A.D., Strain M.C., Farkas O., Malick D.K., Rabuck A.D., Raghavachari K., Foresman J.B., Ortiz J.V., Cui Q., Baboul A.G., Clifford S., Cioslowski J., Stefanov B.B., Liu G., Liashenko A., Piskorz P., Komaromi I., Martin R.L., Fox D.J., Keith T., Al-Laham M.A., Peng C.Y., Nanayakkara A., Challacombe M., Gill P.M.W., Johnson B., Chen W., Wong M.W., Gonzalez C., Pople J.A. Gaussian03, revision C.02. Gaussian Inc, Wallingford, 2004.

17. (a) Schultz T., Quenneville J., Levine B., Toniolo A., Martínez T.J., Lochbrunner S., Schmitt M., Shaffer J.P., Zgierski M.Z., Stolow A. // J. Am. Chem. Soc. - 2003. - 125. - P. 8098/8099; (b) Yager K.G., Barrett C.J. // Photochem. Photobiol., C. - 2006. - 182. - P. 250 - 261.

18. (a) Baskin J.S., Bañares L., Pedersen S., Zewail A.H. // J. Phys. Chem. - 1996. - 100. - P. 11920 - 11933 ;

(b) Quenneville J., Martinez T.J. // J. Phys. Chem. - 2003. - 107A. - P. 829.

19. (a) Aihara J. // Theor. Chem. Acc. - 1999. - 102. - P. 134 -138; (b) Yoshidaa M., Aihara J. // Phys. Chem. Chem. Phys. - 1999. - 1. - P. $227-230$.

20. El Halabieh R.H., Mermut O., Barrett C.J. // Pure Appl. Chem. - 2004. - 76. - P. 1445 - 1465. 